\title{
Melting characteristics of ice blocks immersed in quies- cent saline water
}

\author{
Shoichiro Fukusako, Masahiko Yamada and Chikara Watanabe \\ Department of Mechanical Engineering, Hokkaido University, Kita-ku N13-W8, Sapporo 060, Japan
}

\begin{abstract}
An experimental and analytical study has been carried out to investigate the melting characteristics of ice blocks immersed in quiescent saline water. A horizontal ice cylinder and both downward- and upward-facing inclined ice plates were used as the testing blocks. The experiments were carried out in $3.5 \%$ (by weight) saline water at ambient temperatures ranging from $1.8^{\circ}$ to $25.0^{\circ} \mathrm{C}$ for all kinds of ice blocks. Ice plates were tested at inclination angles from $0^{\circ}$ to $75^{\circ}$. For downwardfacing ice plates, melting rates were determined analytically using the profile method.
\end{abstract}

\section{NOMENGLATURE}

$\mathrm{C}_{\mathrm{p}} \quad$ Specific heat, $\mathrm{kJ}(\mathrm{kg} \mathrm{K})^{-1}$

$g$ Gravitational acceleration, $\mathrm{m} \mathrm{s}^{-2}$

$L \quad$ Latent heat of fusion of ice, $\mathrm{J} \mathrm{kg}^{-1}$

$S \quad$ Concentration of salt, \% by weight

$t \quad$ Time, $\min$

$T$ Temperature, ${ }^{\circ} \mathrm{C}$

$T_{\mathrm{fp}} \quad$ Melting temperature of ice, ${ }^{\circ} \mathrm{C}$

$\Delta T$ Temperature difference $\left(T_{\infty}-T_{\mathrm{fp}}\right),{ }^{\circ} \mathrm{C}$

$V_{\mathrm{i}} \quad$ Melting velocity, $\mathrm{ms}^{-1}$

$x \quad$ Distance from bottom end of the ice plate, $\mathrm{m}$

$y$ Normal distance from the ice surface, $\mathrm{m}$

$\beta \quad$ Coefficient of thermal expansion, ${ }^{\circ} \mathrm{C}^{-1}$

$\beta^{*} \quad$ Coefficient of concentration expansion, $\%^{-1}$

$\delta_{c} \quad$ Thickness of concentration boundary layer, $\mathrm{m}$

$\delta_{\mathrm{TH}}$ Thickness of thermal boundary layer, $\mathrm{m}$

$\delta_{\text {rev }}$ Thickness of velocity inverse layer, $m$

$\delta_{\mathrm{v}} \quad$ Thickness of velocity boundary layer, $\mathrm{m}$

$\theta \quad$ Inclination angle from horizontal, deg

$\lambda$ Thermal conductivity, $\mathrm{W}(\mathrm{m} \mathrm{K})^{-1}$

$\nu \quad$ Kinematic viscosity, $\mathrm{m}^{2} \mathrm{~s}^{-1}$

$\rho \quad$ Density, $\mathrm{kg} \mathrm{m}^{-3}$

\section{Subscripts \\ m Average \\ o Ice surface \\ $\infty \quad$ Ambient \\ i Ice}

\section{INTRODUCTION}

When glaciers move into the sea and melt, they exert effects on both temperature and concentration fields in the sea, and consequently may affect marine biological systems and climates.

Melting characteristics of such ice blocks as those from
Arctic glaciers depend closely on the flow field around them. In the quiescent fluid, free convection which is promoted by both temperature and concentration fields exerts considerable influences on the melting characteristics. Experimental and analytical studies on the melting characteristics of vertical ice plates in saline water have been carried out by Josberger and Martin (1981). However, when an ice block actually melts in sea water, its shape and orientation change continuously.

In the present study, an investigation of the melting heat-transfer characteristics from an ice block immersed in quiescent saline water was performed both experimentally and analytically to obtain basic data applicable to the melting of ice blocks in the sea.

\section{EXPERIMENTAL APPARATUS AND PROCEDURES}

A bubble-free ice block, shaped in prescribed dimensions $(60 \mathrm{~mm}$ in diameter for an ice cylinder and $250 \mathrm{~mm} \times$ $400 \mathrm{~mm} \times 40 \mathrm{~mm}$ for an ice plate), was installed in an insulated saline-water vessel with a lucite plate, $800 \mathrm{~mm}$ wide, $270 \mathrm{~mm}$ long and $910 \mathrm{~mm}$ high. The block was attached to a cooled tube or plate, the temperatures of which were lowered so that the ice block stuck to it.

The experiments were carried out in saline water of a concentration $3.5 \%$ by weight. Thermophysical properties of the water were determined as functions of temperature and salinity (Kukulka and others, 1987). Initial temperature of the water and inclination angle for the ice plates were set as one of the parameters. Just after the ice block, which was initially kept uniform at an equilibrium temperature for $3.5 \%$ concentration, was immersed in the water, observations of the melting behavior and visualizations of flow patterns were carried out, and photographs were taken continuously for a prescribed period. The local melting heat-transfer coefficient was determined by the local melting velocity, 
which was evaluated by photographically recorded ice contours.

\section{ANALYSIS}

\section{Assumptions and basic equations}

The following assumptions have been introduced in performing the analysis for the case of the downwardfacing ice plate:

1. Fields of velocity, temperature, concentration and moving-boundary velocity are independent of time.

2. Temperature and concentration at the ice surface are uniform.

3. Temperature within the ice is uniformly equal to the ice-surface temperature.

4. Flow is two-dimensional, laminar and incompressible.

5. Density depends on both the temperature and concentration; all other properties are constant.

The $x$ - and $y$-axes are set along the ice surface and the normal directions, respectively, as shown in Figure 1. The following equations are obtained from the above assumptions. The continuity equation is

$$
\frac{\partial u}{\partial x}+\frac{\partial v}{\partial y}=0
$$

The momentum and energy equations are

$$
\begin{aligned}
& u \frac{\partial u}{\partial x}+v \frac{\partial u}{\partial y}= \nu \frac{\partial^{2} u}{\partial y^{2}}+C g \beta\left(T-T_{\infty}\right) \\
&+C g \beta^{*}\left(S-S_{\infty}\right) \sin \theta \\
& C=1: y=0 \sim \delta_{\text {rev }} \\
& C=-1: y=\delta_{\text {rev }} \sim \delta_{\nu} \\
& u \frac{\partial T}{\partial x}+v \frac{\partial T}{\partial y}=\kappa \frac{\partial^{2} T}{\partial y^{2}}
\end{aligned}
$$

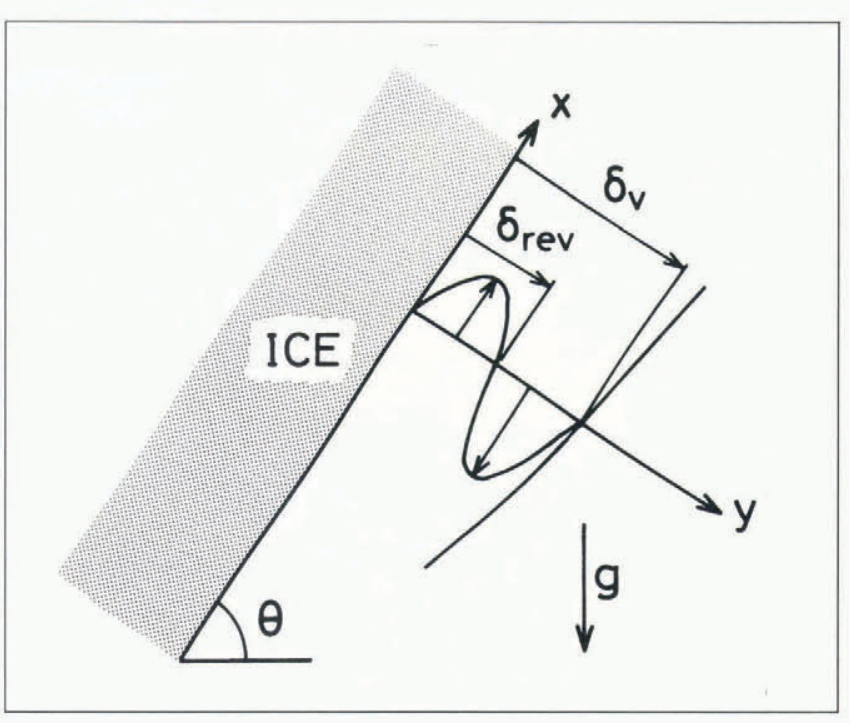

Fig. 1. Coordinate system in analysis.
The diffusion equation is

$$
u \frac{\partial S}{\partial x}+v \frac{\partial S}{\partial y}=D \frac{\partial^{2} S}{\partial y^{2}} .
$$

\section{Boundary conditions}

From heat, mass and concentration fluxes at the ice surface, the following boundary conditions are given as

$$
\begin{aligned}
\lambda\left(\frac{\partial T}{\partial y}\right)_{y=0} & =-L \rho_{\mathrm{i}} V_{\mathrm{i}}, \\
-S_{0}\left(\rho_{\mathrm{i}} / \rho_{0}\right) V_{\mathrm{i}} & =D\left(\frac{\partial S}{\partial y}\right)_{y=0}, \\
v_{0} \rho_{0} & =-v_{\mathrm{i}} \rho_{\mathrm{i}} .
\end{aligned}
$$

From the condition of non-slip, uniform temperature and uniform concentration at the ice surface $(y=0)$,

$$
U=0, \quad T=T_{0}, \quad S=S_{0} .
$$

From the condition for each boundary layer, and at the interface between double boundary layers,

$$
\begin{array}{ll}
y=\delta_{\nu} ; & u=0 \\
y=\delta_{\mathrm{TH}} ; & T=T_{\infty} \\
y=\delta_{\mathrm{c}} ; & S=S_{\infty} \\
y=\delta_{\text {rev }} ; & u=0 .
\end{array}
$$

Equations (1)-(4) were solved under the above boundary conditions using a profile method. Melting rate was determined numerically from calculated results of temperature, concentration and velocity fields.

\section{RESULTS AND DISCUSSION}

\section{Melting characteristics of ice and flow patterns}

Figures 2 and 3 show the flow fields of the ambient fluid and the shapes of both downward- and upward-facing ice plates after $24 \mathrm{~min}$ had elapsed from the start of the experiment. For both cases, the figures show that the thickness of the lower part of the ice plate decreases as the angle of inclination increases, while the average thickness of the ice plate is almost independent of the inclination angle.

As for the downward-facing horizontal ice plate (Fig. 2a), the ambient fluid approaches from both the right and left sides to the center, where it changes into downward flow. Though the turbulence of the ambient fluid flow increases, the thickness of the boundary layer of the meltwater increases as the inclination angle increases to the vertical. For the upward-facing plate, the ambient fluid was taken into the upward flow of the meltwater from both the right and left sides; this flow decreases, while the upward flow of the meltwater causes an increase in its velocity. This may be the reason why the inclination angle exerts little effect on the melting rate. 

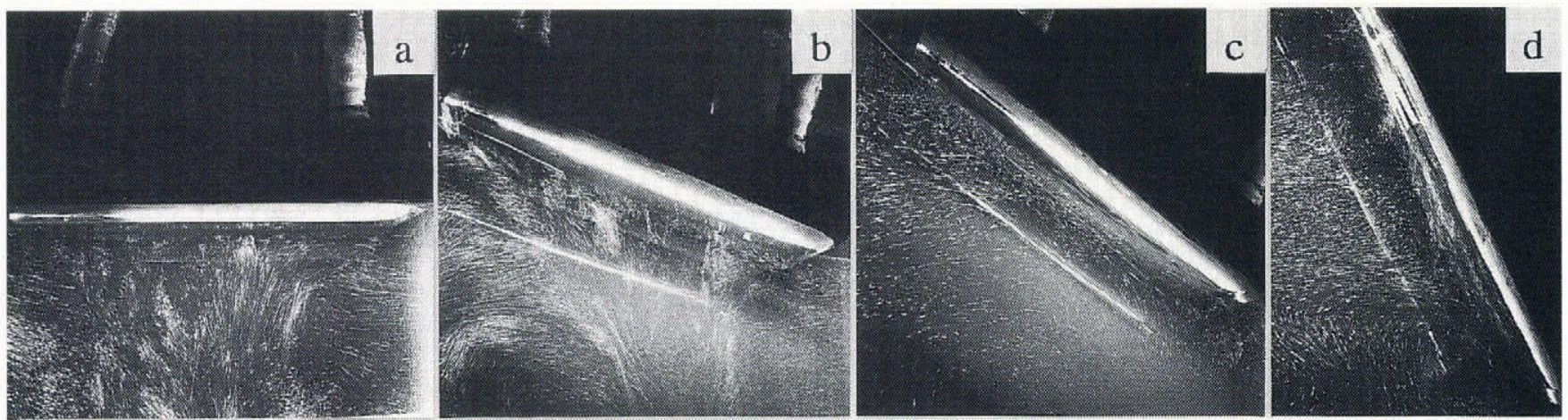

Fig. 2. Effect of inclination angle on melting characteristics (downward-facing): $T_{\infty}=12.0^{\circ} \mathrm{C}, 24$ min elapsed; $a, \theta=0^{\circ} ; b$, $\theta=15^{\circ} ; c, \theta=30^{\circ} ; d, \theta=60^{\circ}$.
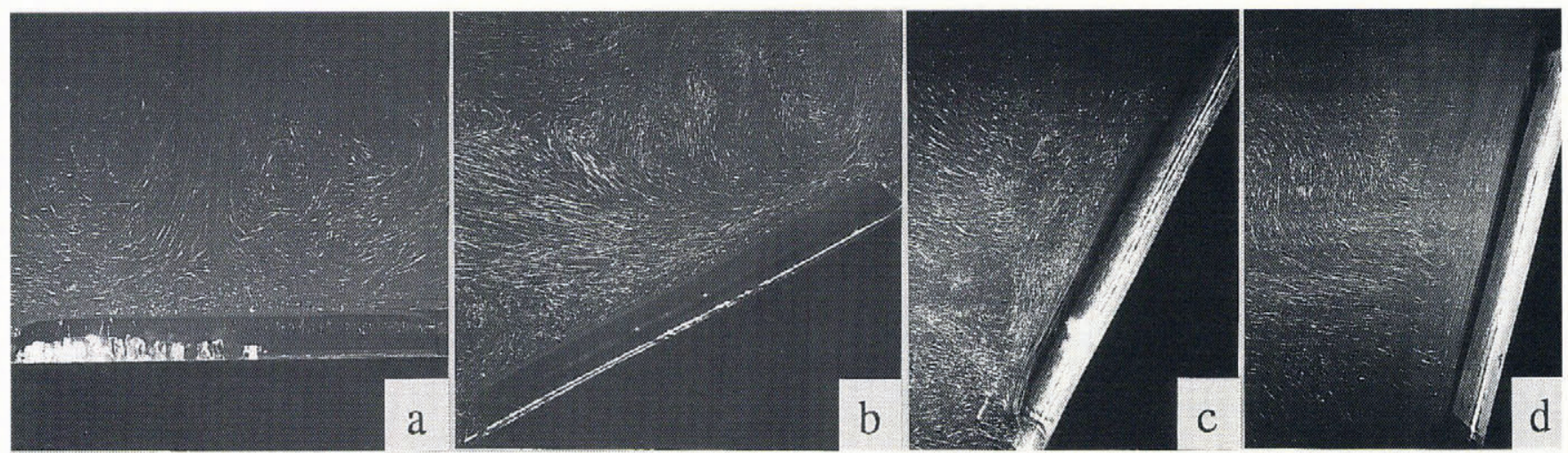

Fig. 3. Effect of inclination angle on melting characteristics (upward-facing): $T_{\infty}=12.0^{\circ} \mathrm{C}, 24 \mathrm{~min}$ elapsed; $a, \theta=0^{\circ} ; b$, $\theta=30^{\circ} ; c, \theta=60^{\circ} ; d, \theta=75^{\circ}$.
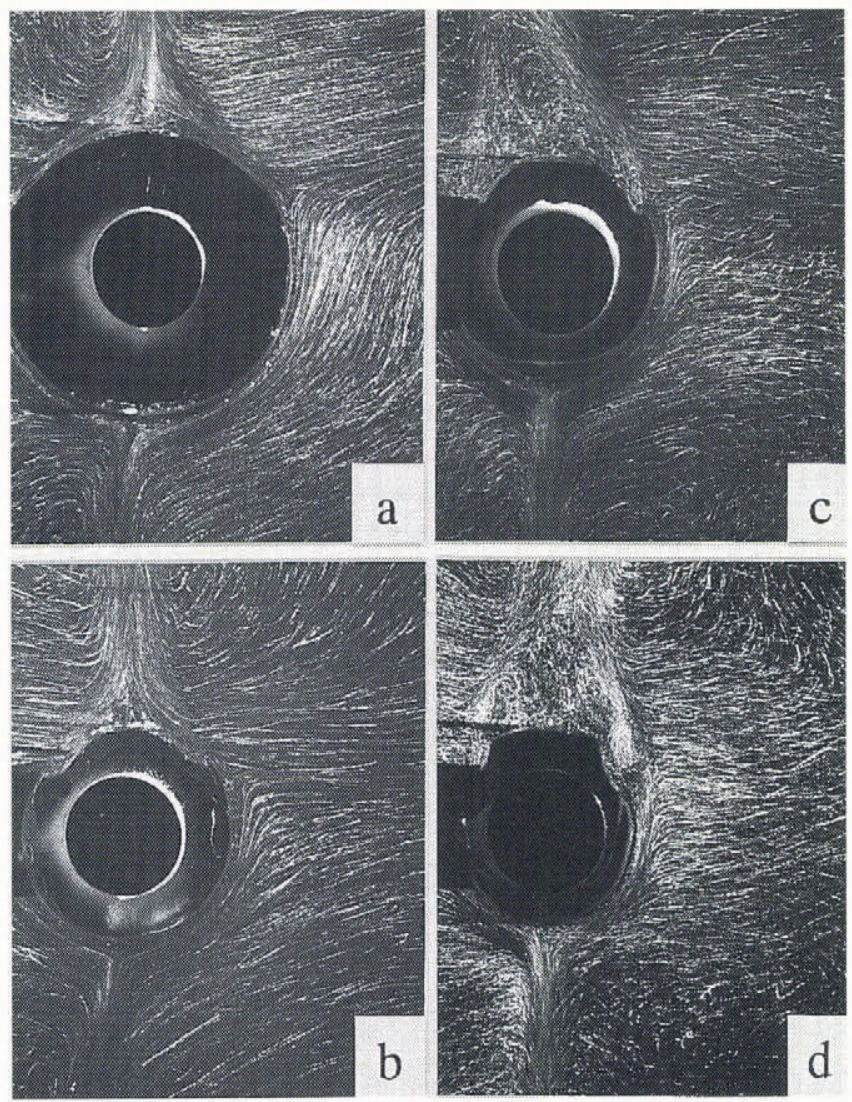

Fig. 4. Melting ice profile and flow pattern around an ice cylinder: $a, T_{\infty}=2.8^{\circ} \mathrm{C}, 15 \mathrm{~min}$ elapsed; $b, T_{\infty}=$ $6.0^{\circ} \mathrm{C}, 15$ min elapsed; $c, T_{\infty}=12.2^{\circ} \mathrm{C}, 2$ min elapsed; $d$, $T_{\infty}=18.0^{\circ} \mathrm{C}, 2$ min elapsed .
Figures 4 and 5, respectively, show variations of the ice-cylinder profiles and schematics of flow patterns. The deviation of the ice-liquid interface from a circular shape results from strong free convection effects. A representative ice profile through melting in all the experiments is that as the melting advances, a step (Fig. 5) forms at the upper part of the ice cylinder, and the flat area near the top of the cylinder tends to increase in size with an increase in far-field temperature $T_{\infty}$.

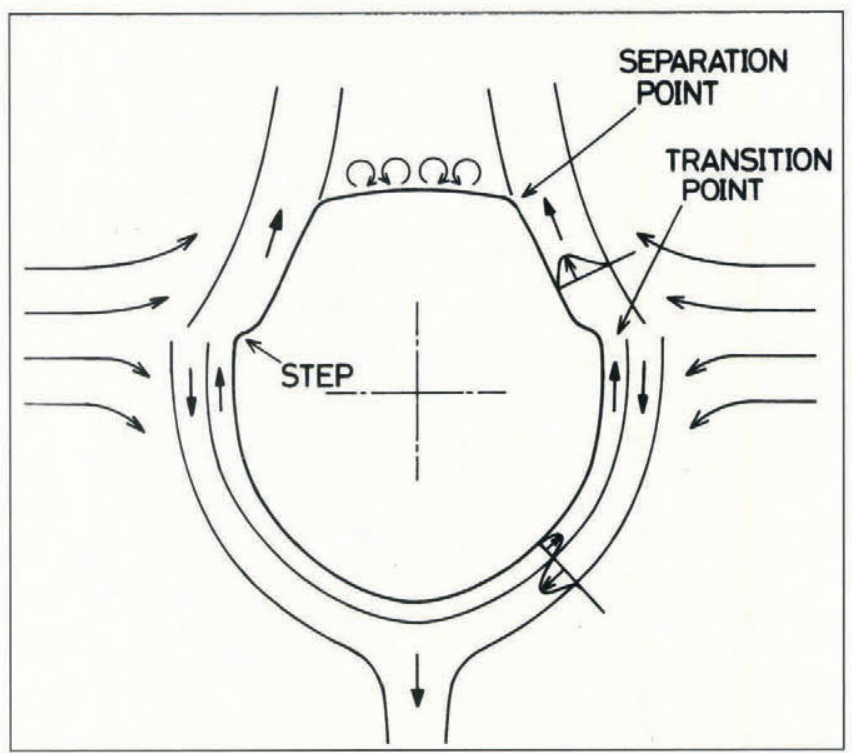

Fig. 5. Flow model around a melting ice cylinder. 


\section{Characteristics of the ice surface}

As in the downward-facing plate, grooves were observed on the ice surface along the flow direction for the upper part of the ice plate, and many small dimples on the ice surface of the lower part (Fig. 6). They are considered to have formed because of secondary flow in the boundary layer of the meltwater.

The effects of the ambient fluid temperature on the melting-surface characteristics of the upward-facing ice plate are shown in Figure 7. For lower ambient

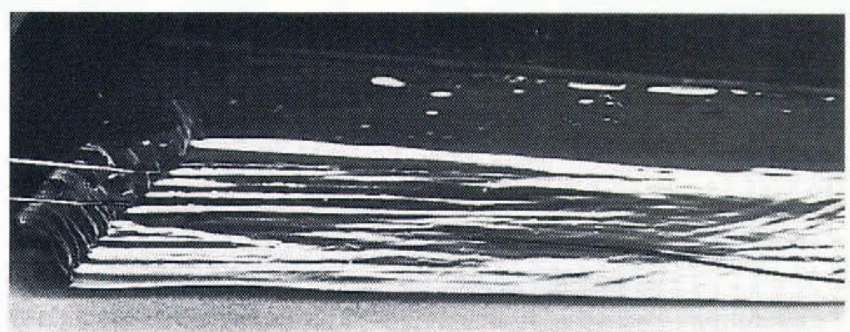

\section{a}

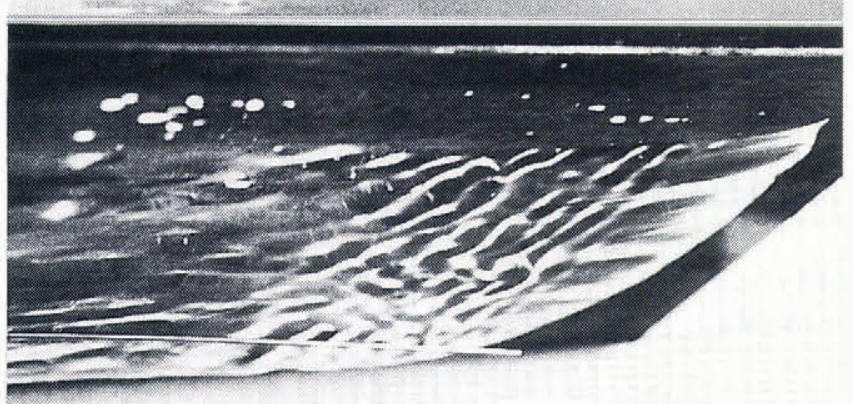

b

Fig. 6. Characteristics of melting ice surface (downwardfacing): $\theta=30^{\circ}$; $a$, upper part of inclined ice plate; $b$, lower part of inclined ice plate.

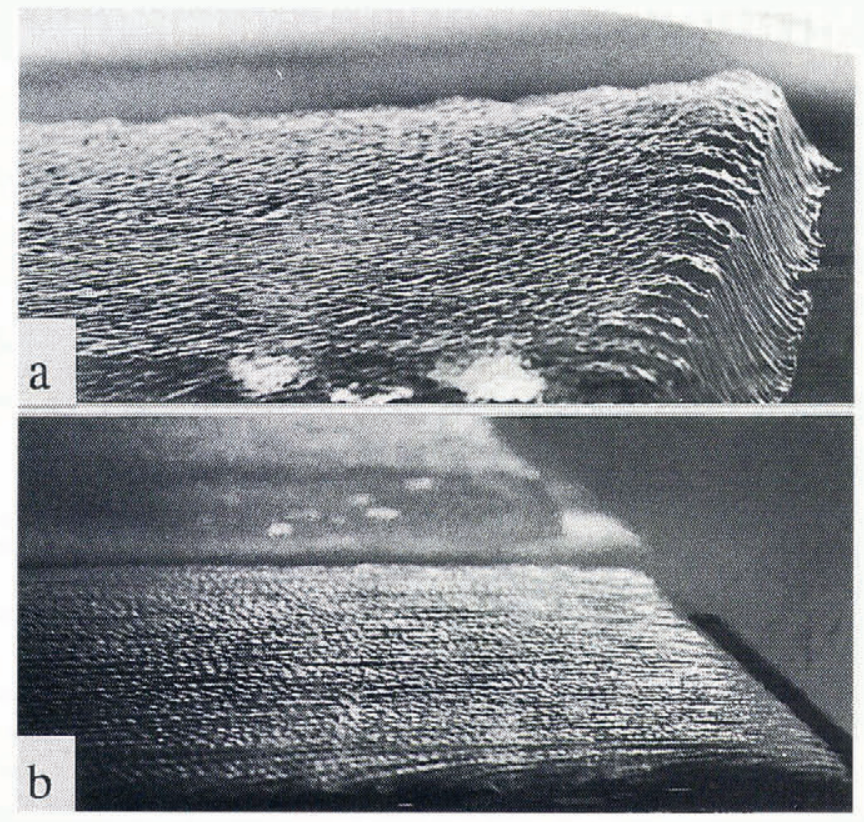

Fig. 7. Characteristics of melting ice surface (upwardfacing): $\theta=15^{\circ} ; a, T_{\infty}=1.0^{\circ} \mathrm{C} ; b, T_{\infty}=18.0^{\circ} \mathrm{C}$.
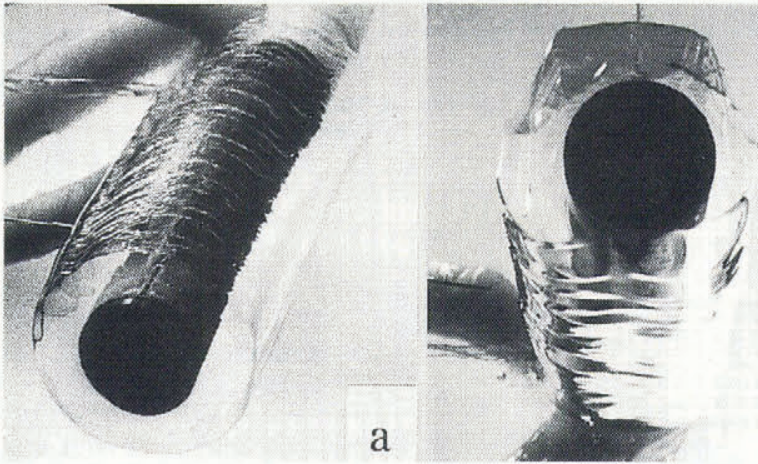

b

Fig. 8. Characteristics of melting ice surface (ice cylinder): $a, T_{\infty}=6.0^{\circ} \mathrm{C}, 15 \mathrm{~min}$ elapsed; $b, T_{\infty}=$ $17.0^{\circ} \mathrm{C}, 20 \mathrm{~min}$ elapsed.

temperatures (Fig. 7a), a lot of small but peculiar dimples are clearly observed on the ice surface. As the ambient temperature increases, these dimples gradually change into grooves along the flow direction (Fig. 6b). Dimples and grooves are formed because of the secondary flow which might be produced by the ambient fluid captured into the meltwater flow.

In the case of the ice cylinder, observational results of the ice-surface characteristics are shown in Figure 8. The surface develops longitudinal grooves with a regular amplitude at that part from step to separation point (Fig. 8a). On the other hand, in the part below the transition point, the melting ice surface is smooth for the lower ambient temperature (Fig. 8b).

\section{Melt-rate characteristics}

Experimental results for average melting velocity in both downward- and upward-facing ice plates are shown in Figures 9 and 10, respectively. For comparison, results for the vertical ice plate (Johnson and Mollendorf, 1984) are indicated by a dotted line in the figures, and analytical results are presented by a solid line in Figure 9. For pure water, melting velocity for an upward-facing horizontal ice plate (Lunardini and others, 1986, p. 23-24) is

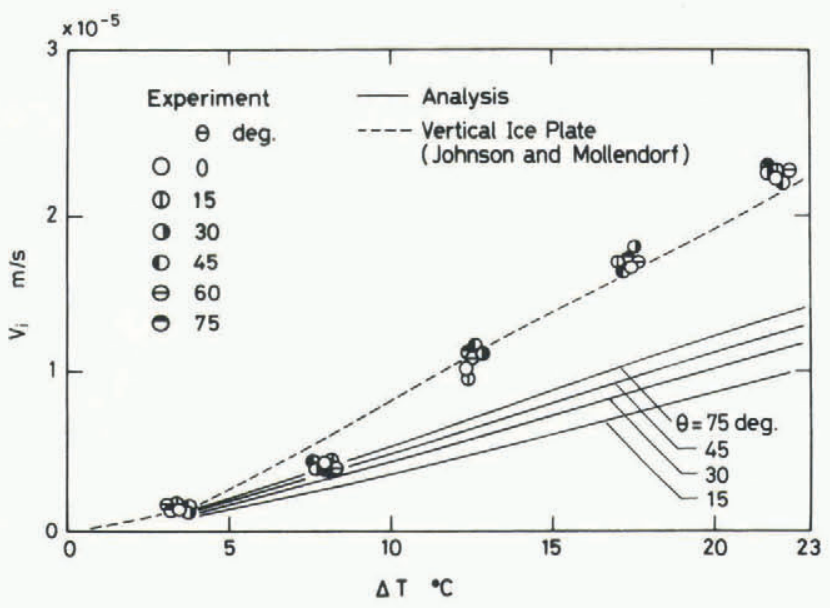

Fig. 9. Melting velocity (downward-facing ice plate). 


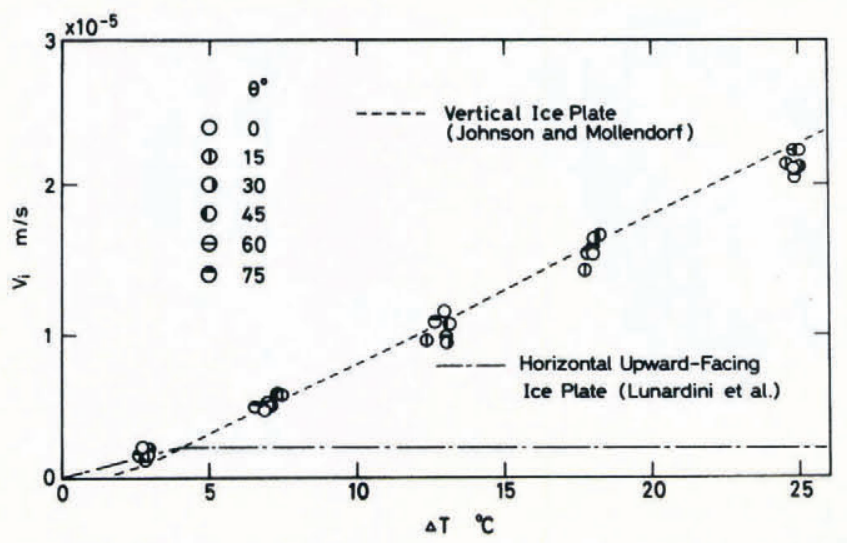

Fig. 10. Melting velocity (upward-facing ice plate).

indicated by a dashed-dotted line in Figure 10. These figures show that, for saline water, the melting rate increases as the temperature difference increases, but is almost independent of the inclination angle.

On the contrary, analytical results of melting rate increase with increasing inclination angle, which agrees well with the experimental results for $\Delta T$ smaller than $8^{\circ} \mathrm{C}$. For $\Delta T$ greater than $8^{\circ} \mathrm{C}$, analytical results are lower than the experimental ones. This is explained by the fact that the effect of the inclination angle on the buoyancy term alone was taken into consideration in the analysis, and that the assumption of laminar flow is no more valid for greater temperature differences.

\section{GONCLUSIONS}

From an examination of melting characteristics of ice blocks immersed in quiescent saline water, determined both experimentally and analytically, the following conclusions may be drawn within the parameter range covered in the present study:

1. For both the ice cylinder and the ice plate, melt rate increases monotonically with ambient temperature, but is almost independent of the inclination angle of the ice plate.

2. Melting characteristics of an ice cylinder depend closely on the ambient temperature.

\section{REFERENCES}

Johnson, R. S. and J. C. Mollendorf. 1984. Transport from a vertical ice surface melting in saline water. Int. J. Heat Mass Transfer, 27, 19281932.

Josberger, E. G. and S. Martin. 1981. A laboratory and theoretical study of the boundary layer adjacent to a vertical melting ice wall in salt water. J. Fluid Mech., 111, 439473.

Kukulka, D. J., B. Gebhart and J. C. Mollendorf. 1987. Thermodynamic and transport properties of pure and saline water. Adv. Heat Transfer, 18, 325-363.

Lunardini, V.J., J.R. Zisson and Y.C. Yen. 1986. Experimental determination of heat transfer coefficients in water flowing over a horizontal ice sheet. CRREL Rep. 86-3.

The accuracy of references in the text and in this list is the responsibility of the authors, to whom queries should be addressed. 